Book Review: Daniel P. Mears, Out-of-Control Criminal Justice: The Systems Improvement Solution for More Safety, Justice, Accountability, and Efficiency. New York: Cambridge University Press. 2017. ISBN: 978-1316614044 (Paperback). 320 Pages. \$22.05

\author{
Reviewed by Rajub Bhowmik ${ }^{1}$
}

[Article copies available for a fee from The Transformative Studies Institute.E-mail address: journal@transformativestudies.org Website: http://www.transformativestudies.org (C2021 by The Transformative Studies Institute. All rights reserved.]

In his book, Out-of-Control Criminal Justice, the Author, Daniel P. Mears provides readers a comprehensive look at the criminal justice system and the need for a system-based approach to criminal justice reform. The book offers a summary of the latest issues in the criminal justice system and the advancement of criminal justice reform. A description of mechanisms and the existence of device problems is given by the author. He describes protection, fairness, transparency, and efficacy as the four primary priorities of the criminal justice system. The book outlines how the new strategy of criminal justice struggles to adequately meet such aims. Mears discusses how an approach to structure enhancement solutions will better meet the aims of the criminal justice system.

The first chapter of the book explains the criminal justice reform challenges and the inability to achieve the targets attributed to system problems. The reviewer discusses framework concerns aligned with the

\footnotetext{
${ }^{1}$ Rajub Bhowmik, DBA, Psy.D., Ph.D., is an Adjunct Assistant Professor of Police Science and Criminal Justice, in the Department of Law, Police Science and Criminal Justice Administration at John Jay College of Criminal Justice of the City University of New York. He also teaches Psychology, in the Department of Behavior and Social Science at Hostos Community College of the City University of New York (CUNY). He is an active law enforcement officer, in the Critical Response Command at CounterTerrorism Bureau of the New York City Police Department. His research interests include serial homicide offender, police and public encounters, police stress, psychology of violence, workplace discrimination and violence, psychology of addictive behaviors, and psychology of corporate culture. Address correspondence to: Rajub Bhowmik, e-mail: rbhowmik@jjay.cuny.edu.
} 
aims of the criminal justice system. The first chapter discusses many of the issues with the criminal justice system, such as recidivism, growing crime rates, "get tough" policies, drug crime, and racial discrimination. The author argues that other concerns, such as civic discontent and a lack of "an institutionalized government accountability apparatus," are scarcely discussed (7). The concerns with the criminal justice system arise from the introduction of strategies that are not focused on proof of their efficacy. The author claims that evidence-based policies are created by the Processes Approach mechanism that can be easily disseminated across the criminal justice system. "The author explains in the book that policy refers to "a wide variety of regulations, guidelines, services, and procedures, as well as decisions taken by policymakers and managers and practitioners of criminal justice (2). A summary of the essence of machine problems is also given in the first chapter. Finally, by explaining the contents of each chapter and the reasons for the Systems Change Approach found in each, the first chapter gives an outline of the structure of the text. By recognizing other fields that deal with common system issues, the second chapter increases the reader's comprehension of processes.

To accomplish the ultimate purpose of making a profit, a manufacturing company process consists of different coherently structured pieces. Any part of the operation must lead to this purpose in one way or another. Even the different components are normal and have lives of their own. Both aspects of the system are defined by "interdependence, and collectively, the activities are more than the sum of their parts (57)". A production firm needs to systematically, frequently, and continuously review every part of its "assembly line" to optimize its products to ensure that it will meet its system target. If a corporation is not seen from a machine prism that explored the interconnectedness of all elements of the system, Mears believes that the company would not succeed in the long run (39). If one component slows down and no longer works correctly (i.e., does not contribute adequately to achieving the overall profit-making purpose of the operation), the fault will be evaluated, measured, and restored, removed, or perhaps even cut depending on the results (Gonzalez, 2021).

Mears finds that the criminal justice system consists of many intertwined "parts and subsystems operating independently and interdependently," like a business process (82). Such subsystems are law enforcement, the judiciary, and corrections, each composed of additional elements and modules that make it highly complicated and impossible to understand the whole framework. Criminal justice programs perform 


\section{Rajub Bhowmik}

various tasks of their own, and their positions can be differentiated, among other factors, within the broader structure, by the physical environments in which they work, the "uniforms" they wear while doing their jobs, and the level of organization in which they operate. Despite these obvious discrepancies, Mears points out that the subsystems are integrated in the sense that they need to work together to accomplish the common objective of the criminal justice system, ensuring public safety and justice while being responsible and effective. Through applying a structured strategy that stresses the interdependence of the multiple elements of the system is striving for a shared purpose, Mears shows that a subsystem of criminal justice will not accomplish public protection and justice on its own. Rather, only with a collective commitment of all framework members will public protection and justice be accomplished.

Despite these obvious discrepancies, Mears points out that subsystems are integrated in the sense that they need to work together to accomplish the common purpose of the criminal justice system, achieving public safety and justice while being responsible and effective. Through applying a structured strategy that stresses the interdependence of the multiple elements of the system is striving for a shared purpose, Mears reveals that a subsystem of criminal justice will not accomplish public protection and justice on its own. Instead, only with a coordinated commitment of all framework members will public safety and justice be accomplished.

Other fields include health care, schooling, protection of the environment, the war on terror, and development. Such examples effectively explain how programs operate. They are effective explanations of how other subsystems are influenced by subsystems and how other parts of the system are affected by changes in one component of a system. This chapter further lists the different kinds of issues in the system and explains how the criminal justice system can be influenced (Carver, Morley, and

Taylor, 2017). The "no-captain issue" and the "intuition and failure-toappreciate issue" seem to be the most critical issues. In the novel, the nocaptain dilemma is illustrated. Through the criminal justice system, it is viewed in the absence of an agency leading the development and execution of criminal justice policies. This lack of a "captain" poses a dilemma when no one is steering the ship and ensuring that the strategy of criminal justice is efficiently analyzed, created, enforced, and checked to ensure that framework priorities are fulfilled. Within the criminal justice system, the institution and failure-to-appreciate dilemma is experienced by the implementation of policies based on intuition and 
ideology rather than analysis based on facts. The author describes the word "correctional quackery" as a term used by some scientists to emphasize policy formulation without evidence-based science (48). A very detailed description of a system and its components is provided in Chapter Three. This chapter discusses the purposes or effects of systems as well as the influences of external forces on systems. The interpretation of the dynamics of processes is the most convincing explanation for systems. It describes the nature of subsystems and the interdependency of subsystems.

This chapter gives further insight into how one subsystem's behavior can influence another subsystem. This is relevant when discussing how any region can be influenced by anything that takes place in one area of the criminal justice system. The sentencing decisions made by the judiciary, for example, will change the number of inmates sent for corrections. A very valuable description of the forms of causal interactions is given by the speaker. In different ways, changes in one subsystem induce changes in other subsystems. Modifications can be overt or indirect. It is noteworthy because when having an equivalent shift in the original subsystem, certain modifications are reversible. Any changes, however, are permanent and cannot be reversed by an inverse shift. The stakeholders need to consider their position and the role of other stakeholders if a System Approach is to be successful. The stakeholder list is long, but researchers and clinicians are two significant members of the list. This is in line with Childs and Potter (2014), who underlines the significance of trust and an appreciation of priorities within the "researcher-agency partnership" (246). As it applies to a machine perspective, Chapter Three also contains a lengthy discussion of philosophy. Especially interesting is the debate about the effect external forces have on structures. The author provides "antifragility" as a definition of a mechanism built to become better by coping with change (74). Mears extends the explanation of a structure to the current criminal justice system in Chapter Four. In the criminal justice system, the author explores the stakes involved, the aims and consequences, the elements, the external forces, the dynamics, philosophy, as well as the faulty solutions. The author highlights the numerous criminal justice initiatives that have been introduced with little or no proof of their success or the presence of a concern that needs a new policy solution (Mears, 2017).

Another feature of the system-unfriendly strategy, as Mears points out several times in the first four pages, is that it appears not to include the broad range of players at all levels - "lawmakers, individuals working in criminal justice, suspects, offenders, victims, communities in which they 


\section{Rajub Bhowmik}

reside, and citizens in general" (195) -the design and execution of the reestablishment of rights. Furthermore, criminal justice policies appear to not be based on results from scientific research but rather on ideological values and philosophy. Consequently, criminal justice departments across the nation are striving for various and potentially divergent shortterm priorities, and the system as a whole is becoming more profoundly fractured, flawed, or downright dysfunctional.

When it comes to juvenile justice policies and financing, the author frequently addresses the gap between jurisdictions. The author emphasizes the point that inequalities do not seem to be focused on crime rate gaps. In the explanations given in this chapter, the influence of external forces is made clear. The author discusses how concerns such as changes in laws and limited funding have a much larger effect on the criminal justice system than real crime does. This chapter further connects criminal justice system operations by a discussion of prisoners as inputs in need of processing. Sadly, the procedure does not efficiently process criminals. The high rate of recurrence is confirmation that criminals require further processing or a new form of processing. Overall, the reader is made mindful of the high costs involved with funding the criminal justice system by Chapter Four. The expense entails several finance amounts and little or little evidence-based rationale for various subsystems. This scenario is like someone being responsible for seasoning food made in a restaurant without a sense of taste. This person has to decide how much seasoning to use without understanding if the flavor of food products is made better or worse by the amount of seasoning. Everything he or she knows is that the boss can have some more when seasonings get low. The boss is like the legislature who, without any awareness of its success, keeps accepting funds for criminal justice services (Enns, 2020).

The final chapter of Chapter 7 outlines the work and sketches the importance of the method briefly. Here, Mears issues a call to action: the present dysfunction can only be brought under control by the introduction of the SIS, the refocusing on public safety, fairness, transparency, and performance, and a complete reorganization of our criminal justice system (246). It is the emphatic appeal of Mears for greater transparency and collaboration among clinicians, scientists, and everyone else influenced by the criminal justice system that renders this book an important guide for reform of criminal justice and a viable solution to explore when grappling with existing system failures. And again, he tells the reader that scientists ought to be active in every phase 
of policy formulation and execution, but their work must still be nonpartisan and deliberative (Wang, Ready, and Davies, 2019).

The author gives a comprehensive overview in Chapter Five of how the Processes Change Approach will operate for defense, justice, transparency, and effectiveness. The focus is focused on the need to conduct analysis on processes and use a method of multi-stakeholder strategy. The need to ensure that strategies, services, procedures, and decision making are all based on facts and not intuition and ideology is often stressed. This chapter acts as a clue to the difficulty of the Approach for Device Change. Several variables have contributed to the criminal justice system's present complexity. Factors such as globalization, the communication revolution, and extremism are described by Trahan and Steward (2013) as contributors to the uncertainty. By offering a viable approach to finding evidence-based alternatives, these researchers complement Mears. They further explain the benefits of mixed-methods analysis, involving both quantitative and qualitative approaches. A comprehensive overview of the advantages of the Systems Improvement Solution and the risks to be avoided is given in Chapter Six.

The advantages listed are focused on the four key objectives of the criminal justice system: defense, justice, transparency, and effectiveness. The pitfalls are mentioned, and suggestions for avoiding those pitfalls are given. Inadequate support for applying the Systems Approach is one of the drawbacks found by the author. Mears argues that legislatures might require that study be devoted to a certain amount of criminal justice funding. This claim is comparable to one put forward by Leverentz (2018), who are both making research investments in the situation. To endorse their demands for new funding and services or to encourage the efficacy of existing programs, criminal justice administrators currently have few evidence-based reviews.

The Systems Reform Approach would demand that management of criminal justice understand the complexity of moving into its complicated execution. Worden, McLean, and Bonner (2014) apply to Oakland Athletics general manager Billy Beane, who understood the importance of data-driven decision-making (286). Before they perform the overwhelming role of adopting it, law justice officials must trust that the application of the Systems Change Solution would be of real benefit to their organization. Another challenge is that this approach needs several different people to join, all of whom would trust in its merit. It will be very hard to adapt the Systems Change Approach mentioned by the author to the criminal justice system effectively. 


\section{Rajub Bhowmik}

There is a desire to change the new criminal justice system. Mears offers a persuasive case for the Device Change Approach to readers. He also proposes thoughtful strategies for solving the different dangers involved. The criminal justice process, however, varies from most schemes. The system of criminal justice is much like the relationship between the federal government and the states. Much when separate states establish legislation based on their philosophies and traditions, their autonomy is favored by the various criminal justice authorities. As an example of a significant disconnect, one may look at the need for the United States Supreme Court to determine the constitutionality of separate statutes and regulations passed by individual states. State officials may refuse to comply with federal officials' opinions.

Federal policymakers will not be able to establish a consensus among states on criminal justice policies. Firstly, the analysis must be based on the device rather than on one or any of its components, as previously mentioned. A lead department must supervise such research. Currently, its fractured nature is a big issue for the modern criminal justice system. The structure lacks the leadership of a "captain" (i.e., a lead criminal enforcement agency) in its present state, who may guide the whole operation in a consistent direction by overseeing a systematic long-term strategy to accomplish its objectives. Mears (2017) worries that it will run "amok, out of control" without a lead department that is "devoted to monitoring and improving the system" (142). Second, the SIS calls for a broad multi-stakeholder strategy, which in the legislative formulation and development process would include everyone who is somehow impacted by the criminal justice system. A collaboration between practitioners and scholars must be established, as meaningful analysis must demonstrate an appreciation of both theory and experience. Also, since they are all critical players, claimants, perpetrators, and the society at large should be included in the process. Finally, the analysis must be evidence-based, consistently and at frequent intervals, and checked. Mears argues that it is only through SIS and these three actions that, with a collective endeavour, we can successfully move towards the shared priorities of the criminal justice system: public protection, justice, transparency, and efficiency.

By having a "captain" agency steering the ship, this problem will not always be overcome. There will be so many organizations that hesitate to step aboard. One may argue that the challenges of the criminal justice system detailed in Mears' book illustrate the need for a mixed-methods approach to criminal justice study and review on a smaller scale. Historically, when examining statistics such as crime rates and 
recurrence rates, the focus has been placed on a quantitative approach. Any commentators may argue that a qualitative approach needs to be given more focus so that concerns such as civic discontent can be properly tackled. Woodward, Webb, Griffin, and Copes (2016) point to the fact that quantitative approaches require less time and are often dependent on "secondary information" (341). Quantitative approaches make it simpler and quicker to perform analysis. The human aspect, however, is not included in scientific data-driven analysis. Although it is possible that incorporating a Systems Reform Approach will be incredibly difficult for criminal justice authorities, Mears opens the reader to fascinating and evocative concepts, and he should be commended for that. This academic work received the prestigious Excellent Book Award from the 2019 Academy of Criminal Justice Sciences. Although detractors may argue that it may take many years, if not decades, to bring some of the solutions proposed in Out of Touch Criminal Justice into motion, Mears has nonetheless written a thoughtful and well-researched book.

\section{REFERENCES}

Carver, L., Morley, S. and Taylor, P., (2017). Voices of the deficit: Mental health, criminal victimization, and epistemic injustice. Illness, Crisis \& Loss, 25(1), pp.43-62. https://doi.org/10.1177/1054137316675715

Childs, K.K., \& Potter, R.H. (2014). Developing and Sustaining Collaborative Research Partnerships with Universities and Criminal Justice Agencies. Criminal Justice Studies: A Critical Journal of Crime, Law \& Science, 27(3), 245-248. https://doi.org/10.1080/1478601x.2014.947810

Enns, P.K., (2020). Mobilized by Injustice: Criminal Justice Contact, Political Participation, and Race. By Hannah L. Walker. New York: Oxford University Press, 2020. 216p. 27.95 paper. Perspectives on Politics, 18(4), pp.1214-1216. https://doi.org/10.1017/s1537592720002844

Gonzalez, A., (2021). Voiceless Development, Toxic Injustice, Criminal Resistance: A Study of Peruvian Natural Resource Extraction Through the Political Ecology of Voice. In Environment and Development (pp. 305-335). Palgrave Macmillan, Cham. https://doi.org/10.1007/978-3030-55416-3 11

Leverentz, A., (2018). Churning through the system: How people engage with the criminal justice system when faced with short sentences. In After Imprisonment. Emerald Publishing Limited. https://doi.org/10.1108/s1059-433720180000077006 


\section{Rajub Bhowmik}

Mears, D. P. (2017). Out-of-Control Criminal Justice: The Systems Improvement Solution for More Safety, Justice, Accountability, and Efficiency. New York: Cambridge University Press. https://doi.org/10.1017/9781316676578.002

Trahan, A., \& Steward, D.M. (2013). Toward a Pragmatic Framework for Mixed-Methods Research in Criminal Justice and Criminology. Applied Psychology in Criminal Justice, 9(1), 59-74.

Wang, X., Ready, J. and Davies, G., (2019). Race, ethnicity, and perceived minority police presence: Examining perceptions of criminal injustice among Los Angeles residents. Law \& Society Review, 53(3), pp.706-739. https://doi.org/10.1111/lasr.12423

Woodward, V.H., Webb, M.E., Griffin, O.H., \& Copes, H. (2016). The Current State of Criminological Research in the United States: An Examination of Research Methodologies in Criminology and Criminal Justice Journals." Journal of Criminal Justice Education, 27(3), 340361. https://doi.org/10.1080/10511253.2015.1131312

Worden, R.E., McLean, S.J., \& Bonner, H.S. (2014). Research Partners in Criminal Justice: Notes from Syracuse." Criminal Justice Studies: A Critical Journal of Crime, Law \& Society, 27(3), 278-293. https://doi.org/10.1080/1478601x.2014.947812 